\title{
Enzymatic activity mastered by altering metal coordination spheres
}

\author{
Isabel Moura $\cdot$ Sofia R. Pauleta $\cdot$ José J. G. Moura
}

Received: 8 April 2008/Accepted: 1 August 2008/Published online: 22 August 2008

(C) SBIC 2008

\begin{abstract}
Metalloenzymes control enzymatic activity by changing the characteristics of the metal centers where catalysis takes place. The conversion between inactive and active states can be tuned by altering the coordination number of the metal site, and in some cases by an associated conformational change. These processes will be illustrated using heme proteins (cytochrome $c$ nitrite reductase, cytochrome $c$ peroxidase and cytochrome $c d_{1}$ nitrite reductase), non-heme proteins (superoxide reductase and $[\mathrm{NiFe}]$-hydrogenase), and copper proteins (nitrite and nitrous oxide reductases) as examples. These examples catalyze electron transfer reactions that include atom transfer, abstraction and insertion.
\end{abstract}

Keywords Enzyme activation - Active site coordination Heme $\cdot$ Copper and non-heme proteins

Abbreviations
$c c$ NIR Cytochrome $c$ nitrite reductase
CuNIR Copper nitrite reductase

CuNIR Copper nitrite reductase

\footnotetext{
I. Moura $(\bowtie) \cdot$ S. R. Pauleta $\cdot$ J. J. G. Moura

REQUIMTE, Centro de Química Fina e Biotecnologia,

Departamento de Química,

Faculdade de Ciências e Tecnologia,

Universidade Nova de Lisboa,

2829-516 Caparica, Portugal

e-mail: isa @dq.fct.unl.pt

S. R. Pauleta

e-mail: srp@dq.fct.unl.pt

J. J. G. Moura

e-mail: Jose.moura@dq.fct.unl.pt
}

\section{Introduction}

Biological systems have developed enzymatic mechanisms and metabolic pathways as a response to environmental pressures and demands. In most cases, the chosen solutions are based on similar features, reflecting the ability of the biological systems to adapt the active site of the biological catalysts to the capture of available substrates.

In this manuscript, metal-containing enzymes are used to illustrate how activation and inactivation is controlled by altering the metal coordination sphere of the active site (or catalytic site). These basic and repetitive coordination patterns may be used to search for adequate ways to carry out valuable and useful biological reactions.

It is well-known that the metal-ligand environment controls enzymatic activity. Enzymes are usually isolated in states that are not ready to interact with the substrate and, in order to generate a catalytically competent form of the enzyme; changes have to occur (designated the "activation step"). These changes can occur by altering the oxidation state of the metal center, through the presence of external ions, through interactions with an electron donor/ acceptor partner, or through incubation with a substrate. Most of these processes will alter the metal coordination sphere (Fig. 1), and in some cases are accompanied by conformational changes that generate an active (ready) state of the enzyme.

This paper aims, in a nonexhaustive way, to demonstrate how metalloenzymes can control enzymatic activity by changing some of the characteristics of the metal centers where the catalysis takes place. Several examples will be given: heme proteins (cytochrome $c$ nitrite reductase, cytochrome $c$ peroxidase and cytochrome $c d_{1}$ nitrite reductase); non-heme proteins (superoxide reductase and 


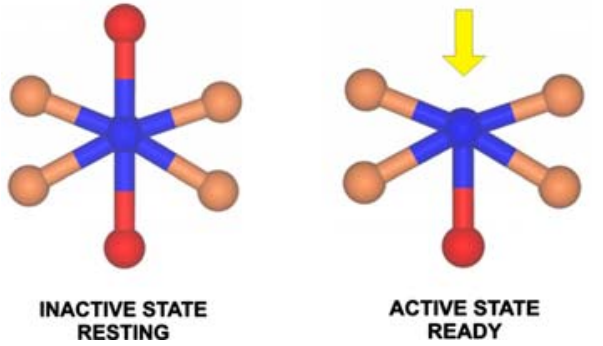

Fig. 1 Schematic representation of a catalytic site in an inactive state and an active state. The enzyme becomes active by changing the coordination of the metal center

$\mathrm{NiFe}$ hydrogenase); and copper proteins (nitrite and nitrous oxide reductases). These illustrate different aspects of the changes that occur at or near the metal-ligand environment. The tuning of the conversion of inactive/active states by changing the coordination number at the metal site followed by concomitant conformational changes is a mechanism used by enzymes to perform very different reactions: atom transfer, abstraction and insertion. Most of these reactions also exhibit coupled proton-electron transfer.

\section{Biochemical reactions and biological systems}

\section{Dissimilatory nitrite reduction-ccNIR}

$\mathrm{NO}_{2}^{-}+8 \mathrm{H}^{+}+6 e^{-} \rightarrow \mathrm{NH}_{4}^{+}+2 \mathrm{H}_{2} \mathrm{O}$.

A multiheme cytochrome $c$ nitrite reductase ( $c c$ NIR) catalyzes the reduction of nitrite to ammonia in a unique sixelectron step $[1,2]$.

\section{Denitrification}

$2 \mathrm{NO}_{3}^{-}+10 e^{-}+12 \mathrm{H}^{+} \rightarrow \mathrm{N}_{2}+6 \mathrm{H}_{2} \mathrm{O}$.

Denitrification is a pathway in the biogeochemical nitrogen cycle that has biological, environmental and industrial value due to its importance in the soil availability of nitrate/ammonia, in greenhouse effect processes (contributing to the release of nitric oxide), and also in wastewater treatment.

This pathway is found in a wide range of organisms, from eubacteria to archaea and even fungi, and enables respiration when oxygen availability is limited [3-7]. This pathway comprises four steps that operate in a complex sequential reaction scheme:

nitrate $\rightarrow$ nitrite $\rightarrow$ nitric oxide $\rightarrow$ nitrous oxide $\rightarrow$ dinitrogen gas.

Over the last few years, a great deal of effort has been expended to unravel the structures of the enzymes involved in this cycle and to understand their mechanisms [8-15].
The global denitrification reaction $\left(2 \mathrm{NO}_{3}{ }^{-}+10 e^{-}+\right.$ $12 \mathrm{H}^{+} \rightarrow \mathrm{N}_{2}+6 \mathrm{H}_{2} \mathrm{O}$ ) can be decomposed into steps where the products of one reaction are the substrate of the following reaction, in a chain mechanism. Three of these reactions involve oxygen transfer/abstraction $(*)$ :

$$
\begin{aligned}
& \mathrm{NO}_{3}^{-}+2 e^{-}+2 \mathrm{H}^{+} \rightarrow \mathrm{NO}_{2}^{-}+\mathrm{H}_{2} \mathrm{O}(*) \\
& \quad(\text { nitrate reductase }) \\
& \mathrm{NO}_{2}^{-}+e^{-}+2 \mathrm{H}^{+} \rightarrow \mathrm{NO}+\mathrm{H}_{2} \mathrm{O}(*)
\end{aligned}
$$

(nitrite reductase)

$2 \mathrm{NO}+2 e^{-}+2 \mathrm{H}^{+} \rightarrow \mathrm{N}_{2} \mathrm{O}+\mathrm{H}_{2} \mathrm{O}$

(nitric oxide reductase)

$\mathrm{N}_{2} \mathrm{O}+2 e^{-}+2 \mathrm{H}^{+} \rightarrow \mathrm{N}_{2}+\mathrm{H}_{2} \mathrm{O}(*)$

(nitrous oxide reductase).

The 3D structures of all the enzymes involved in this pathway, with the exception of nitric oxide reductase, have been determined recently. These enzymes employ a wide range of transition metals in their active sites, namely Mo, $\mathrm{Fe}$ and $\mathrm{Cu}[8-15]$.

\section{Detoxification of reactive oxygen species}

As mentioned, denitrification is induced at low oxygen concentrations. In prokaryotes, during the transition period to anoxic conditions, there is a restriction in the flow of electrons in the respiratory chain that generates high levels of hydrogen peroxide, which in turn induces not only the expression of genes involved in the denitrification (due to the anoxic conditions) but also a detoxifying enzyme, cytochrome $c$ peroxidase, as a defense mechanism against the cytotoxic effects of hydrogen peroxide [16]. Cytochrome $c$ peroxidase is a periplasmic enzyme that catalyzes the twoelectron reduction of hydrogen peroxide to water $\left(\mathrm{H}_{2} \mathrm{O}_{2}+\right.$ $2 \mathrm{H}^{+}+2 e^{-} \rightarrow 2 \mathrm{H}_{2} \mathrm{O}$ ). This enzyme has an intriguing activation mechanism that will be discussed later [17-19].

Another enzyme used by microorganisms as a defense mechanism against reactive oxygen species is superoxide reductase. This enzyme, found in anaerobic organisms, catalyzes the reduction of superoxide anion to hydrogen peroxide $\left(\mathrm{O}_{2}^{--}+e^{-}+2 \mathrm{H}^{+} \rightarrow \mathrm{H}_{2} \mathrm{O}_{2}\right)$, and can be isolated in an equilibrium between the active and inactive state [20-22].

\section{Hydrogen consumption/production-hydrogenase}

$2 \mathrm{H}^{+}+2 e^{-} \rightleftharpoons \mathrm{H}_{2}$.

Hydrogenases are a group of enzymes that also require activation steps and the removal of ligands from metal coordination spheres. This enzyme carries out the simplest oxidation-reduction reaction: proton reduction and hydrogen oxidation [23, 24]. 


\section{Case studies}

The examples that will be discussed are organized as follows:

Case 1. Enzymes that are ready for action The enzymes that fall in this category are those that do not require a change at the metal site to perform their role. Two examples are the nitrite reductases $c c$ NIR (cytochrome $c$ nitrite reductase, also denominated NrfA), which reduces nitrite to ammonia [2, 13, 25], and CuNIR (copper nitrite reductase), which reduces nitrite to NO [6, 26, 27].

Case 2. Enzymes that are "almost there": equilibrium between active/inactive states Some enzymes can be isolated either in an inactive or active state. Moreover, in some cases the metal site exhibits an equilibrium between an active/inactive state due to the binding of a protein ligand. The example that will be discussed is the superoxide reductase [20-22].

Case 3. Enzymes that are isolated in unready states that require activation Here, enzymes that are isolated in an inactive state, and for which activation involves structural modifications, will be considered. The inactive enzyme has a full coordination sphere, but the removal of a crucial ligand generates a site for the binding of a substrate. Reductive steps may be largely responsible for attaining the active state of the enzyme, as will be discussed. The examples chosen are: cytochrome $c$ peroxidase, cytochrome $c d_{1}$ nitrite reductase, $[\mathrm{NiFe}]$-hydrogenase and nitrous oxide reductase.

Case 1: Enzymes that are ready for action

\section{Nitrite reductases-ccNIR and CuNIR}

In the dissimilative ammonification process, the reduction of nitrite to ammonia occurs in a unique six-electron step,

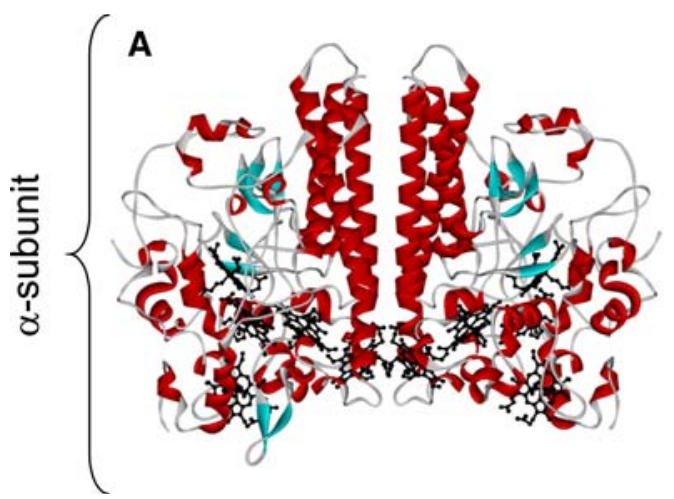

Fig. 2 Structure of the $\alpha$-subunit of Desulfovibrio desulfuricans ccNIR (1OAH.pdb). a View of the dimer structure with the backbone colored according to secondary structure and the heme groups are colored black. b View of the heme groups in the same orientation as and is catalyzed by $c c \mathrm{NIR}$, a pentaheme cytochrome $c$ nitrite reductase (also denoted NrfA) [25]. The cofactors are five hemes $c$ that are covalently attached to the enzyme through two thioether linkages to cysteine residues. The enzyme is an oligomer with two subunits $\left(\alpha_{6} \beta_{3}\right)$ [28]. The catalytic site is located in the $\alpha$ subunit and can be easily identified as heme 1 , since it is the only heme that has a lysine as the single axial ligand and a new CXXCK hemebinding motif, whereas all of the others are bis-histidinecoordinated (Fig. 2).

This enzyme is ready to react with the substrate due to the vacant coordination position at the catalytic site (heme 1). This site is occupied by a water molecule in the crystal structure. The other four hexacoordinated hemes function as electron donors.

Another example where no activation step is required before the reaction with the substrate is copper nitrite reductase [29-31]. This enzyme is a trimer with two types of copper centers. One of the copper centers is a "type 1" (blue) copper with a distorted tetrahedral geometry. The four ligands (two His, Cys, Met), from the same polypeptide chain, fully occupy the coordination sphere of the metal. The other is a "type 2" copper center with three histidine residues and one water molecule acting as the "fourth" ligand. This center is located between two monomers, with the ligands coming from two polypeptide chains, and is the catalytic site while the other center acts as its electron donor (Fig. 3) [11, 27, 32].

In both of these examples, the enzymes are isolated in the active state and are ready to interact with the substrate. The catalytic site is easily identified in the structures, as it is the only metal center that has a water molecule completing the coordination sphere of the metal, and it is well known that water is a weak ligand that can be easily replaced by the substrate.

B

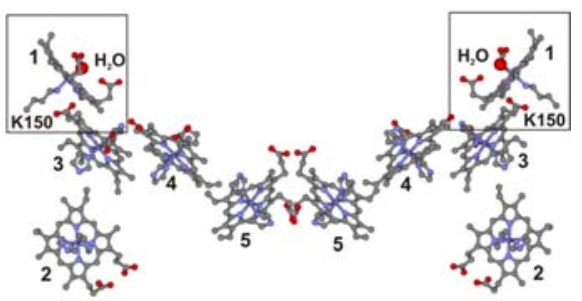

in a. The hemes are colored according to element, and the figure shows that hemes $2-5$ are bis-histidine-coordinated, while heme 1 presents a lysine and a water molecule as axial ligands. The figures were created with DSViewer Pro 5.0 

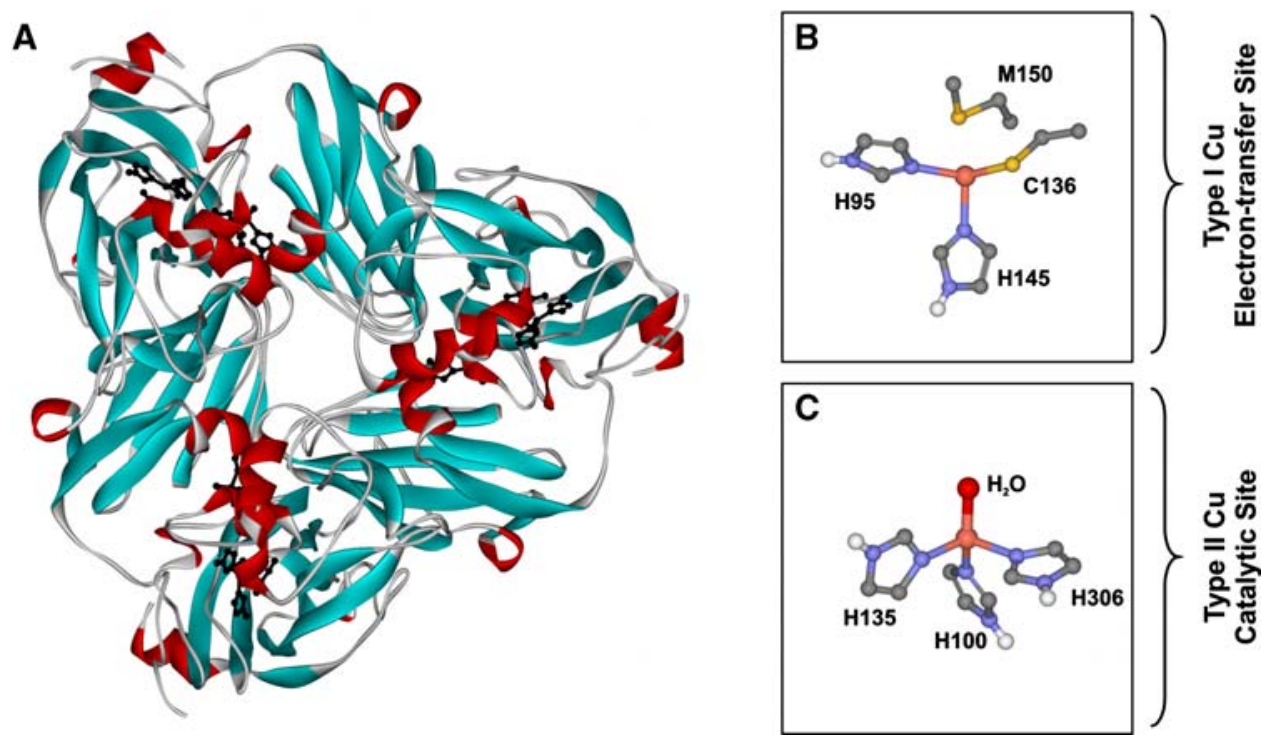

Fig. 3 Structure of Alcaligenes faecalis copper-containing nitrite reductase (1AS7.pdb). a View of the trimer structure with the backbone colored according to secondary structure; the copper atoms and their ligands are shown in black. b View of two copper sites: electron transfer and catalytic sites. At the electron transfer site, $H 95$, C136, H145 and M150 side chains from the same polypeptide chain

Case 2: Enzymes that are "almost there": equilibrium between active/inactive states

Same enzyme can be in either the inactive or the active state, depending on the organism it is isolated from. In others, an equilibrium between the inactive and active states can be observed. Superoxide reductase (SOR), which catalyzes the reduction of the superoxide anion to hydrogen peroxide [22, 33, 34], falls into this category. This family of enzymes can be divided into different classes depending on the presence of one or two types of non-heme iron centers [35]. At the catalytic center, which is common to all classes, four equatorial histidine side-chain residues and one axial cysteine residue coordinate the iron atom, $\left[\mathrm{Fe}(\mathrm{NHis})_{4} \mathrm{SCys}\right]$ [36]. In some cases, an additional rubredoxin-like iron-sulfur center, $\left[\mathrm{Fe}(\mathrm{SCys})_{4}\right]$ [37], of unknown function, is found attached to the polypeptide chains of these enzymes, in a different domain from the catalytic site. The third class of SOR also presents this additional domain, but there is no metal center [21].

In the oxidized inactive states of some of these enzymes, a glutamate side chain is bound to the iron atom of the catalytic site as its sixth axial ligand, occupying the vacant position where the substrate is proposed to bind (Fig. 4) [38-40]. This glutamate residue is highly conserved in superoxide reductases and is located in a flexible solventexposed loop, which appears disordered in the crystal structures of some of these enzymes [21,36]. It is proposed that, upon reduction, the glutamate is displaced (Fig. 4) and coordinate the "type 1 " copper, while in the active center, the "type 2" copper is coordinated by three histidine side chains (H1OO, H135 and H306 from the neighboring polypeptide chain) and a water molecule. The copper atoms, the side chains of the copper ligands and the water molecule are colored according to element. The figures were created with DSViewer Pro 5.0 (Accelrys)

plays an important role in the catalytic mechanism, assisting the release of hydrogen peroxide [38-40].

However, in the structure of the oxidized superoxide reductase from Treponema pallidum, the catalytic iron site is pentacoordinated, and the corresponding glutamate residue is found 10-12 $\AA$ away from the metal [21]. In some of the molecules of the asymmetric unit, a water molecule could be fitted to the electron density found in close proximity to the iron atom $(2.6 \AA)$, in a similar position to that observed in the catalytic center of the reduced enzyme from Pyrococcus furiosus [36].

It has also been shown that the axial coordination by the glutamate side chain is $\mathrm{pH}$-dependent, and that at higher $\mathrm{pH}$ (above 9) it can be substituted by a hydroxide as an axial ligand for the iron atom [41, 42].

Recently, the analysis of an increasing number of complete genomes has shown that, although this glutamate residue is conserved, its position in the sequence might not enable the coordination of the iron center in a resting oxidized state [43]. The metal centers of these types of enzymes are ready to interact with the substrate.

Case 3: Enzymes isolated in unready states that require activation

Following the examples of enzymes that are isolated in a ready state (or in equilibrium between the ready and resting state) and do not require many structural changes to attain catalytic activity, we will now focus on enzymes that 

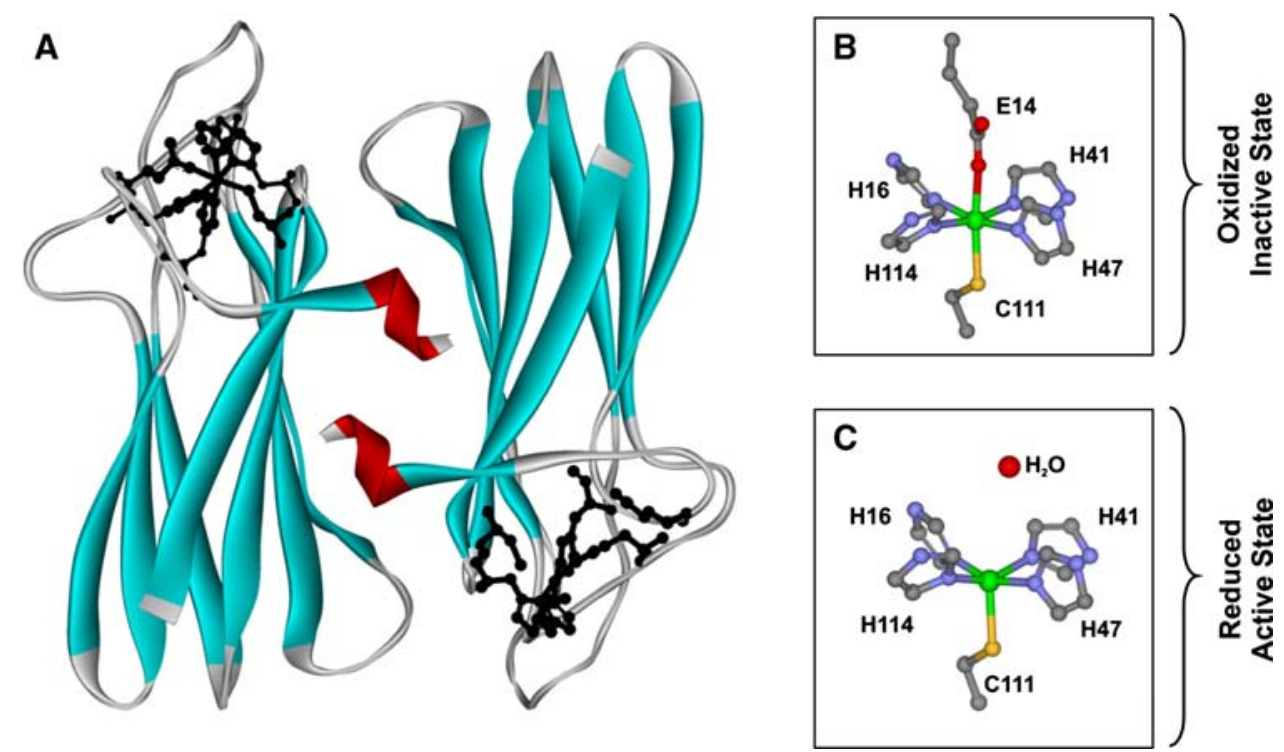

Fig. 4 Structure of superoxide reductase from Pyrococcus furiosus. The enzyme is a dimer and displays an immunoglobulin-like fold (a), with the catalytic center located at one end (colored in black). When the catalytic center is oxidized (b), the iron center is hexacoordinated by four histidine side chains, one cysteine and one glutamate. In the reduced form (c), the glutamate side chain is displaced and there is a

require an activation step in order to build a site where the substrate can bind to the metal cofactor: a ready (active) site. In some cases, this activation step requires drastic conformational changes for the enzyme to become active, and the metal coordination sphere has to be controlled to an extent in order to ensure that the reaction with the substrate occurs only when the site is available, and there must be sufficient electrons to carry out the complete reaction.

Moreover, the enzymes illustrated here share some other common features in terms of both their activation steps and domain architectures. Their tertiary structures are organized in such a way that two metal sites are created and hosted: an electron transfer site and a catalytic site. In these enzymes, the overall reaction rate depends on an intermolecular electron transfer from a specific electron donor to the electron transfer site (or vice versa), as well as an intramolecular electron transfer step from the electron transfer site to the catalytic site (Fig. 5).

\section{Cytochrome c peroxidase and cytochrome $\mathrm{cd}_{1}$ nitrite reductase}

Bacterial cytochrome $c$ peroxidase is a dimeric periplasmic enzyme that catalyzes the two-electron reduction of hydrogen peroxide to water [16]. Each monomer contains two hemes: the electron-transfer heme (E heme) and the peroxidatic heme ( $\mathrm{P}$ heme). The electron transfer heme is a high-potential heme and receives electrons from small electron donor proteins that are also present in the water molecule in close proximity to the iron atom. The ligands of the iron center are colored according to element; the iron atom is shown in green and the water molecule as a red sphere. The figures were created with DSViewer Pro 5.0 (Accelrys), using 1DQI.pdb (a and b) and 1DQK.pdb (c)

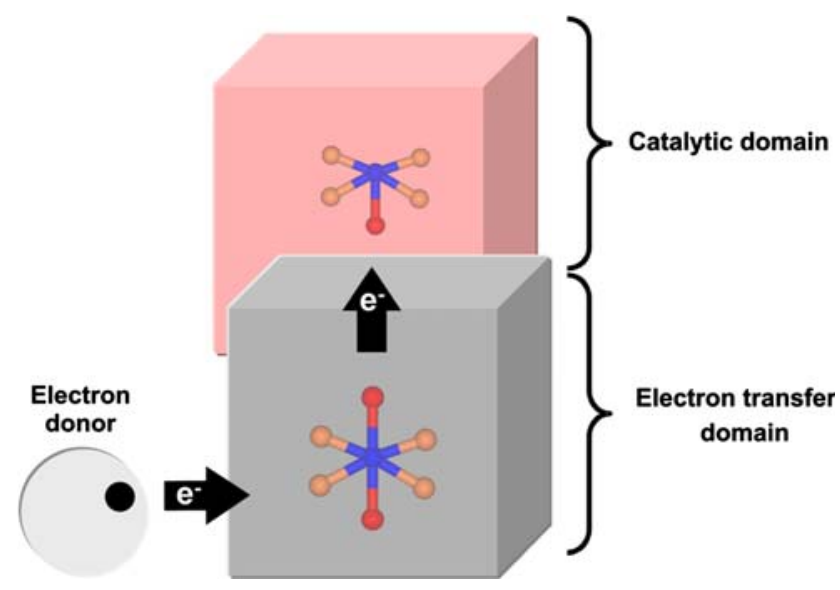

Fig. 5 Schematic representation of the domain architecture of cytochrome $c$ peroxidase and cytochrome $c d_{1}$ nitrite reductase, which is also common to other enzymes presented here. In the catalytic domain, the metal center is represented in the activated form, ready to bind the substrate

periplasm (heme- $c$ or "type 1" copper proteins) [44-46]. The peroxidatic heme is a low-potential heme and is the catalytic site where the reaction occurs. In the native, asisolated state, both hemes are hexacoordinated: the electron-transfer heme has Met-His coordination and the peroxidatic heme is coordinated by two histidine side chains. In order to become active, the enzyme needs to receive one electron into the electron-transfer heme and also requires bound calcium ions [45]. In vitro studies have shown that bound calcium ions are essential for enzyme 
activity; however, under physiological conditions it is probable that the enzyme always has bound calcium.

Therefore, in the presence of calcium ions, and coupled to the reduction of the electron-transfer heme, a conformational change occurs in the polypeptide chain, mainly around the peroxidatic heme [18]. The peroxidatic heme loses one of the histidine axial ligands and becomes pentacoordinated and ready to react with the substrate [18, 19]. In the absence of calcium, the reduction of the electrontransfer heme does not promote the conversion of the peroxidatic heme into the pentacoordinated form, and the enzyme remains inactive. Both forms have been crystallized from the enzyme isolated from Pseudomonas nautica, and are compared in Fig. 6 [17].

The domain in gray contains the electron-transfer heme and the domain in pink the peroxidatic heme. The

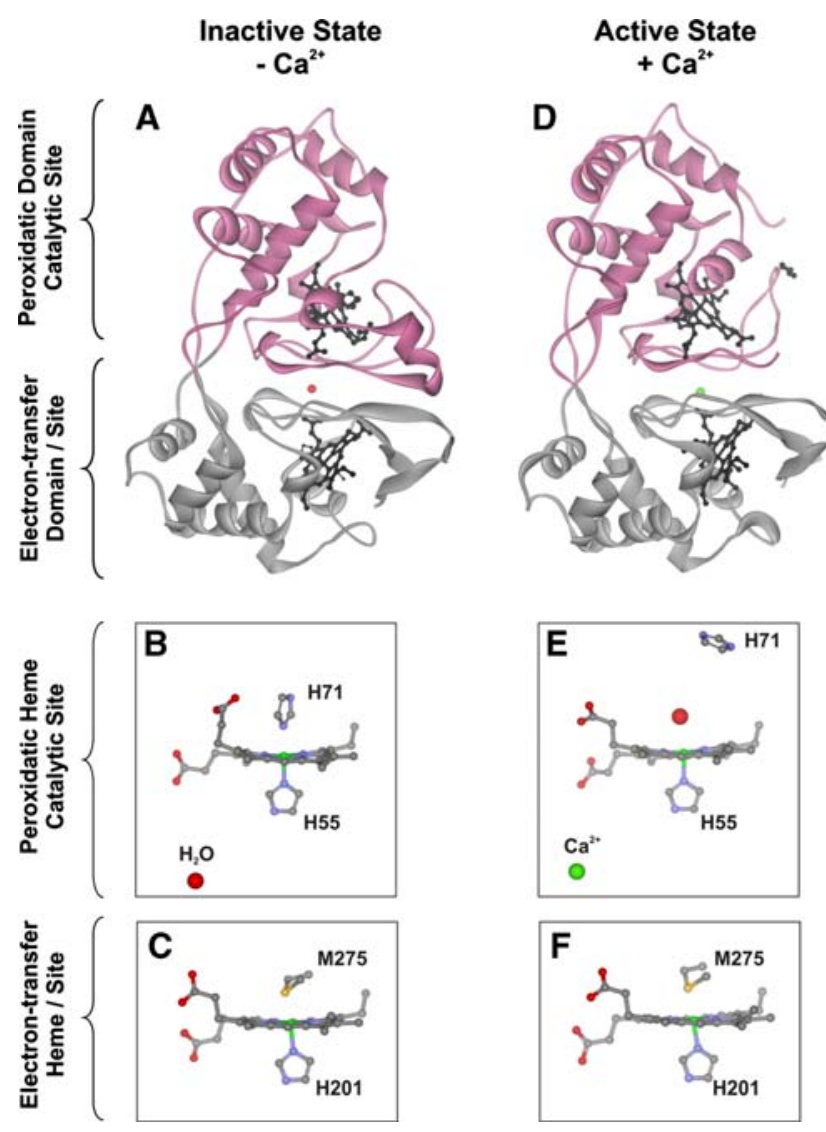

Fig. 6 View of the monomer of bacterial cytochrome $c$ peroxidase from Pseudomonas nautica in the inactive $(\mathbf{a}-\mathbf{c})$ and active $(\mathbf{d}-\mathbf{f})$ states. The electron-transfer domain, in gray, exhibits identical folding in both states, while the peroxidatic domain, in pink, shows a conformational change upon calcium binding (green sphere), with one of the histidine ligands of $\mathrm{P}$ heme (c) being displaced and a water molecule taking its place (f). The iron atom is colored green and the heme and iron ligands are colored by element. The figures were produced with DSViewer Pro 5.0 (Accelrys) using 1RZ6.pdb (a-c) and 1RZ5.pdb (d-f) differences are striking: the loop containing the histidine that coordinates the peroxidatic heme in the inactive form is out in the active form.

Comparing the electron-transfer domains of the two forms, it can be seen that the electron-transfer heme presents Met-His coordination in both cases, but there are subtle differences at the level of the interface with the peroxidatic domain. More striking are the differences in the peroxidatic domain: in the presence of calcium ions, the loop containing the His is completely out, allowing the substrate to approach.

The calcium ion is positioned between the two domains and is coordinated by both water molecules and residues from the polypeptide chain. The presence of this calcium ion might be important for positioning a tryptophan residue in the correct orientation for electron transfer between the two hemes. When calcium is not present, the side chain of this tryptophan residue is not in the proposed electron pathway between the two hemes. The importance of this residue in both the activation and catalytic activity of the enzyme has been shown through mutagenesis studies [47].

Cytochrome $c d_{1}$ nitrite reductase is also a periplasmic dimeric enzyme with two different domains that is isolated in an inactive state [7]. One of the domains contains a covalently attached heme $c$ and the other binds heme $d_{1}$. Heme $c$ controls electron transfer, while heme $d_{1}$ is the catalytic center. Relevant changes occur during the activation process: when both centers are in the oxidized form, the coordination sphere of the heme $d_{1}$ iron is fully occupied with a tyrosine side chain and a histidine side chain as axial ligands (Fig. 7c) [12, 48].

After reduction, concomitant changes occur in the coordination sphere of heme $c$ and heme $d_{1}$ : the tyrosine side chain is displaced and a coordination site is vacant for the substrate to bind to heme $d_{1}$. Nitrite binds through the nitrogen atom (Fig. 7f) and it is possible to observe a form with the product of the reaction (NO) bound to the heme $d_{1}$ in the crystal structure [12]. Changes were also detected at the level of heme $c$. In the "as-isolated" form of the enzyme, when both hemes are oxidized, heme $c$ has bishistidinyl coordination (Fig. 7b), but after reduction it becomes Met-His-coordinated (Fig. 7e), which indicates that both hemes act in a concerted way.

It was found by electrochemistry that inter- or intramolecular electron transfer can control the rate of reduction of $\mathrm{NO}_{2}{ }^{-}$to $\mathrm{NO}$, depending on the $\mathrm{pH}$. At low $\mathrm{pH}$, the intermolecular electron transfer rate (cytochrome $c_{552}$ to cytochrome $c d_{1}$-heme $c$ ) is limiting, which avoids the formation of $\mathrm{Fe}(\mathrm{II})-\mathrm{NO}$. At high $\mathrm{pH}$, the rate constant for the intramolecular electron transfer decreases and becomes limiting, which enables the formation of Fe(II)-NO [49].

Recently, it has been proven that the release of NO from reduced heme $d_{1}$ is faster than or comparable to the 
Inactive State
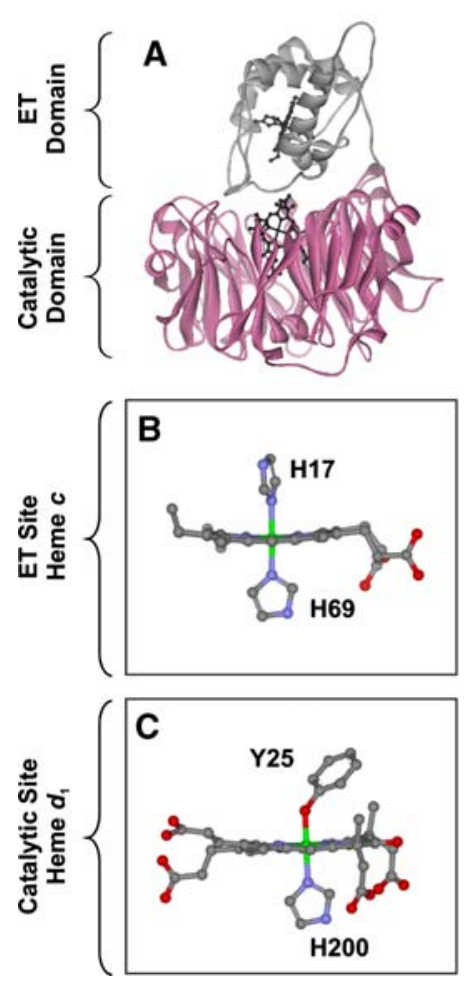

Active State
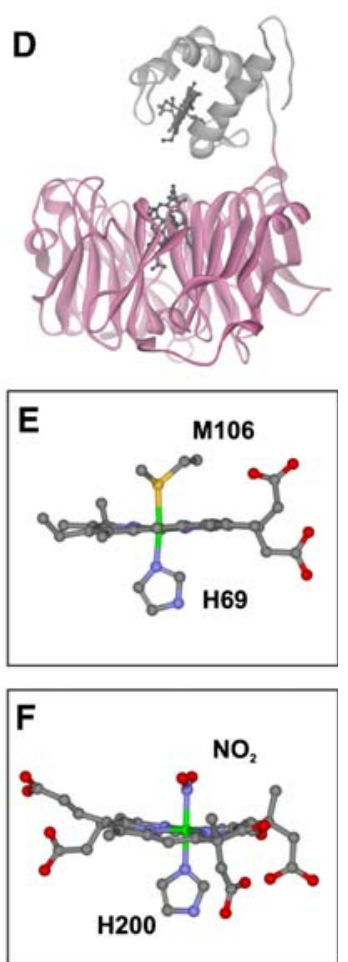

Fig. 7 View of the monomer of cytochrome $c d_{1}$ nitrite reductase from Paracoccus denitrificans in the inactive state (a-c) and active state (d-f). In the oxidized state, heme $c$ is coordinated by $H 17$ and $H 69$ (b), while heme $d_{1}$ is coordinated by $H 200$ and $Y 25$ (c). When the enzyme is activated by reduction, H17 is substituted by M106, an axial ligand of heme $c(\mathbf{e})$; simultaneously, Y25 is displaced from heme $d_{1}$ and a vacant position is available for the binding of the substrate, nitrite, as shown in f. The figures were created with DSViewer Pro 5.0 (Accelrys) using 1QKS.pdb (a-c), 1AOF.pdb (d, e) and 1AOM.pdb (f)

turnover number, contrary to expectations, and that reduced or oxidized heme $d_{1}-\mathrm{NO}$ can both take part in the catalytic cycle [50].

$\mathrm{Ni}-\mathrm{Fe}$ hydrogenase

There are two types of hydrogenases: the iron-only and the nickel-iron hydrogenases [24, 51]. The nickel-iron hydrogenases are $\alpha \beta$ heterodimers composed of a small ( $\beta$-subunit) and a large subunit ( $\alpha$-subunit), whose structures have been determined from different organisms [23]. The small subunit contains three iron-sulfur clusters, and the larger subunit holds a binuclear $\mathrm{Ni}-\mathrm{Fe}$ cluster; the catalytic site. The heterometallic cluster is maintained by four Cys ligands: two of them bridge the iron and the nickel ions (Fig. 8), while the other two complete the nickel coordination sphere (in some hydrogenases, the nickel ion presents a selenium cysteine, $\mathrm{Se}-\mathrm{Cys}$, as ligand). The iron ion presents more unusual ligands: a carbon monoxide molecule and two cyanide ions $[52,53]$.

Although several intriguing questions have been raised over the last few years, most of them have already been addressed: the identity of the iron ligands; the redox state of the metals; the spin delocalization between the iron and nickel ions; the nature of the bridging ligand $\mathrm{X}$; the interaction of $\mathrm{H}-\mathrm{H}$ with the nickel ion; and whether the nickel ligands are involved in catalysis [24].

The nature of the ligand $\mathrm{X}$ and its role in the activation of hydrogenase is a key question. The as-isolated enzyme is inactive and becomes active after long-term exposure to hydrogen gas. Inactive oxidized states of $\mathrm{NiFe}$ Hases have been named based on their EPR spectrum as $\mathrm{Ni}-\mathrm{A}\left(\mathrm{Ni}^{3+}\right.$, $\left.\mathrm{Fe}^{2+}\right)$ and $\mathrm{Ni}-\mathrm{B}\left(\mathrm{Ni}^{3+}, \mathrm{Fe}^{2+}\right)[54,55]$. During this incubation period, the EPR signals assigned to the inactive state (namely $\mathrm{Ni}-\mathrm{A}$ ) disappear and are slowly converted to another species, named $\mathrm{Ni}-\mathrm{C}\left(\mathrm{Ni}^{3+}, \mathrm{Fe}^{2+}\right)$ (EPR-detectable) and to further reduced states (EPR-silent, $\mathrm{Ni}^{2+}, \mathrm{Fe}^{2+}$ ) [56-59]. On this basis Ni-A, Ni-B and Ni-C have been denoted "inactive" (unready), "ready" and "active," respectively. It is well known that the nickel ion interacts

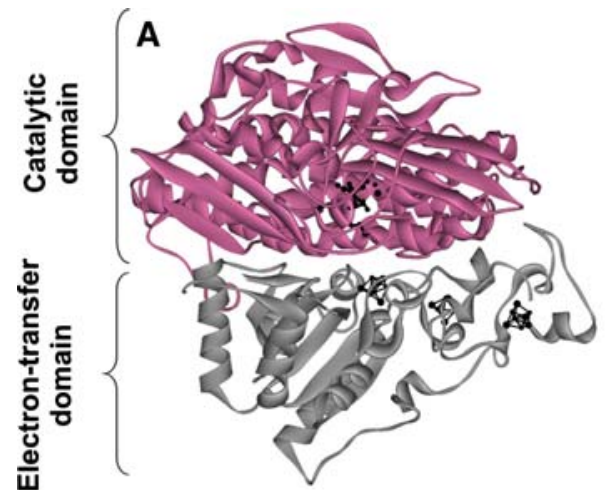

Fig. 8 a View of [Ni-Fe]-hydrogenase from Desulfomicrobium baculatum, with the large subunit shown in pink and the small subunit in gray. The iron-sulfur centers and the catalytic center are in black. The catalytic centers in the Ni-A ("unready" form from
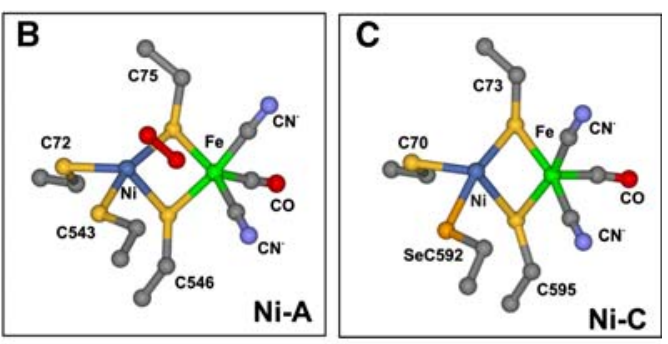

Desulfovibrio fructosorovans) state and Ni-C (active state) are shown in $\mathbf{b}$ and $\mathbf{c}$, respectively. In $\mathbf{b}$, the diatomic oxygen species is shown in red. The figures were created with DSViewer Pro 5.0 (Accelrys) using 1CC1.pdb (a, c) and 1YQW.pdb (b) 
with the substrate, and one proposal is that one of the nickel ligands acts as the proton acceptor while the nickel ion is the hydride acceptor [24].

The as-isolated hydrogenase does not react with the substrate due to the presence of an oxygen species as a ligand of the nickel ion, ligand $\mathrm{X}(\mathrm{NiA})$. The activation of the enzyme in the presence of hydrogen gas and its reoxidation in the presence of $\mathrm{H}_{2}{ }^{17} \mathrm{O}$ introduces a ${ }^{17} \mathrm{O}$ label in the $\mathrm{Ni}^{3+}$ oxidized state, which supports the presence of an oxygencontaining species as a $\mathrm{Ni}-\mathrm{Fe}$ bridging ligand [60].

This ligand "blocks" the catalytic site in the inactive (Ni-A) state of the enzyme, and must be removed to allow the hydrogen gas to react with the ready/active state of hydrogenase (Ni-C). These results were supported by X-ray crystallography, which showed that hydrogenase in the inactive state $(\mathrm{Ni}-\mathrm{A})$ presents a diatomic molecule (possibly a hydroperoxide) that bridges the iron and the nickel ions, and that in the reduced active state this ligand is absent in the reduced active state (Fig. 8) [52, 53, 61]. A $\mu$-hydroxo is proposed to be the bridging ligand in the $\mathrm{Ni}-\mathrm{B}$ state. These different bridging ligands between the $\mathrm{Ni}$ and Fe centers could be responsible for the different reactivities of the enzymatic species.

\section{Nitrous oxide reductase}

The enzyme that participates in the last step of denitrification, the nitrous oxide reductase $\left(\mathrm{N}_{2} \mathrm{OR}\right)$ that converts nitrous oxide to dinitrogen [62], is another interesting case.
The enzyme is a homodimer; each monomer has two domains that hosts two different types of copper centers [8]. The $\mathrm{N}$-terminal domain has a $\beta$-propeller structure with seven blades. The catalytic site, CuZ, a tetranuclear copper center, is found in this domain (Fig. 9). The C-terminal domain has a cupredoxin-like domain, and contains a binuclear copper center, $\mathrm{CuA}$, similar to that found in cytochrome $c$ oxidase (Fig. 9) $[8,9]$.

The structural motif that divides the protein into two different functional domains that accommodate an electron-transfer and a catalytic site is observed again. However, in the case of nitrous oxide reductase, the two redox centers are $40 \AA$ apart in the same subunit, but only $10 \AA$ apart between the subunits, attributing a more prominent functional role to the dimer [9].

The electron-transfer center, $\mathrm{CuA}$, is a "type 3" copper center that has two cysteine residues as bridging ligands and two histidines, one methionine and one tryptophan as the other copper ligands (Fig. 9b). However, the catalytic center, $\mathrm{CuZ}$, is an unusual and unique copper center composed of four copper atoms. All of the copper atoms (except $\mathrm{Cu}^{\mathrm{IV}}$ ) have two histidine ligands, and there is a sulfur atom that bridges all four copper atoms. Another ligand, present between $\mathrm{CuIV}$ and $\mathrm{CuI}$, is proposed to be $\mathrm{OH}$ or $\mathrm{H}_{2} \mathrm{O}$ (Fig. 9c, d) [8, 9, 63, 64].

EPR, MCD, EXAFS and DFT calculations indicate that $\mathrm{CuA}$ exists in a mixed valence state with one $\mathrm{Cu}^{2+}$ and one $\mathrm{Cu}^{1+}$. The electron is shared between the two copper atoms. In the case of $\mathrm{CuZ}$, the formal oxidation state is
Fig. 9 View of nitrous oxide reductase from Paracoccus denitrificans. a The dimer of nitrous oxide reductase is colored according to subunit. One monomer is colored in light gray, while in the other, the catalytic domain with the $\mathrm{CuZ}$ center is pink, and the electrontransfer domain with the $\mathrm{CuA}$ center is dark gray. b The $\mathrm{CuA}$ center and $\mathbf{c}$ the $\mathrm{CuZ}$ center. An oxygen atom, presented as a red sphere, is located in-between $\mathrm{Cu}^{\mathrm{I}}$ and $\mathrm{Cu}^{\mathrm{IV}}$ of the $\mathrm{CuZ}$ center. d The $\mathrm{CuZ}$ center of a pink form of Achromobacter cycloclastes nitrous oxide reductase, where a water molecule and a hydroxide are present in-between $\mathrm{Cu}^{\mathrm{I}}$ and $\mathrm{Cu}^{\mathrm{IV}}$. The ligands of the copper atoms are colored according to element. The figures were created with DSViewer Pro 5.0 (Accelrys) using 1FWX.pdb (a-c) and 2IWF.pdb (d)
A
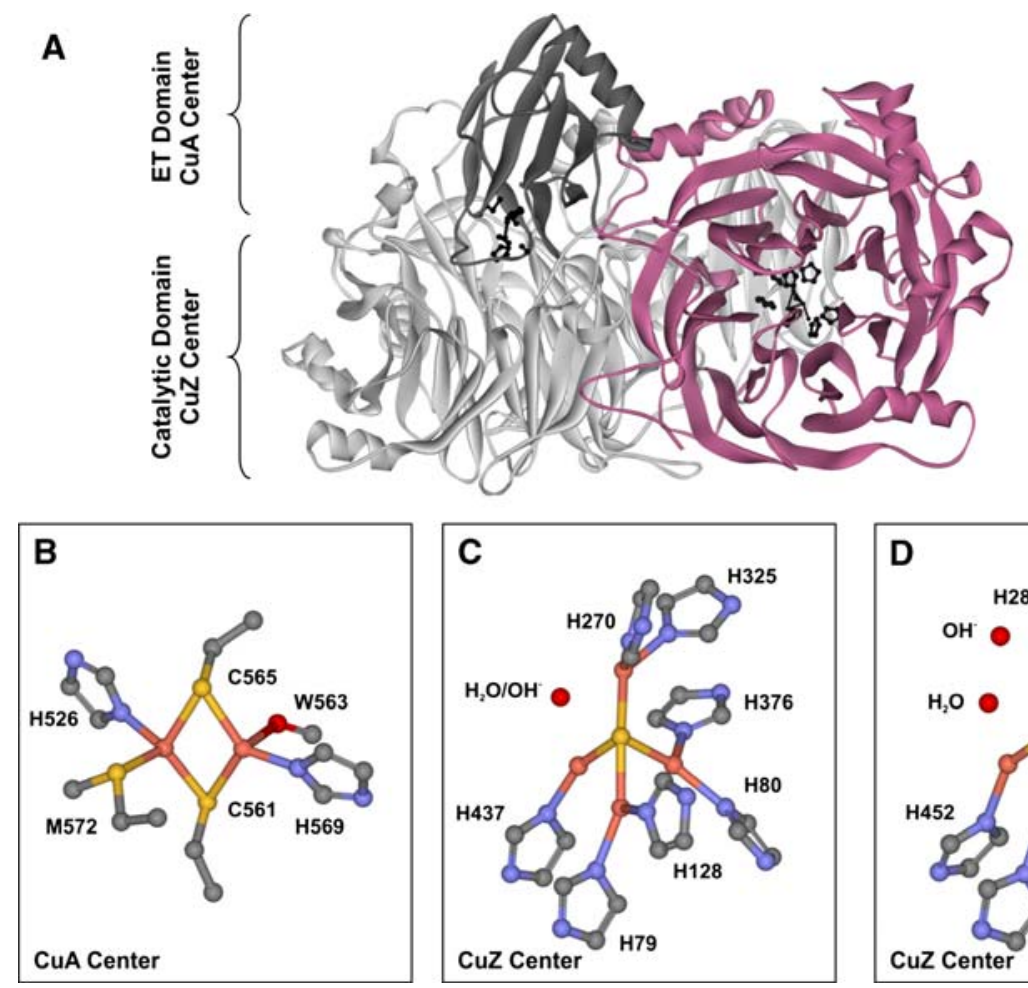
given as three $\mathrm{Cu}^{1+}$ and one $\mathrm{Cu}^{2+}$. Addition of dithionite reduces the $\mathrm{CuA}$ center with the $\mathrm{CuZ}$ center maintaining its formal oxidation state [64-68]. This form of the enzyme corresponds to an inactive form. In order to be active, the enzyme requires prolonged incubation in the presence of reduced methyl viologen, which fully reduces $\mathrm{CuZ}$ to four $\mathrm{Cu}^{1+}[66]$.

There are two possible ways for the $\mathrm{N}_{2} \mathrm{O}$ molecule to bind to CuZ. Theoretical calculations suggest that the $\mathrm{N}_{2} \mathrm{O}$ molecule binds to the fully reduced state of the $\mathrm{CuZ}$ center, in a $\mu-1,3 \mathrm{~N}_{2} \mathrm{O}$ bridging mode. Elongation of the $\mathrm{O}-\mathrm{N}$ bond and the creation of a negative charge on the $\mathrm{N}_{2} \mathrm{O}$ molecule facilitates the cleavage of the bond. An oxygen atom is left behind after $\mathrm{N}_{2}$ release, and the protein has two fewer electrons. Therefore, two electrons must enter the enzyme and two protonation steps have to occur in order for the enzyme to return to its initial state. This is accomplished through efficient electron pathways [69-71].

\section{Final remarks}

It is a general observation that nature has to deal with a wide range of chemical reactions and molecules. Biology has evolved biosynthetic routes to produce these molecules in a conserved mode and uses pathways that have common features optimized for different needs. Biological systems use metabolic pathways and mechanisms that are the result of evolutionary demands, and the most efficient are selected. The basic feature seems to be the use of modular systems, through which small modifications create an enormous biodiversity.

One clear example is the porphyrin ring system, where a basic common structure is adopted to produce variations (such as heme $c$, heme $b$ and heme $d$ ) — the heme may or may not be covalently linked to the polypeptide chain and a wide variety of ligands and metals can also be incorporated $(\mathrm{Fe}$, $\mathrm{Ni}, \mathrm{Co}, \mathrm{Mg}$ ). Iron-sulfur clusters built up from a basic tetrahedral arrangement of $\mathrm{Fe}$ and sulfur are another example.

In addition to metal centers, some reactions present common mechanistic aspects. For example, oxygen abstraction is usually carried out by metal centers that weaken bonds: the oxygen atom is abstracted and transformed into an easy leaving group by protonation, enabling the regeneration of the catalyst in a simple fashion.

In this review we have focused on case studies where the metal-ligand environment controls enzymatic activity. A common pattern has been described, again within a general framework of optimization. Metalloenzymes are usually isolated in states that are not ready to interact with the substrate, and most of these biological catalysts require an activation step. In order to generate a catalytically com- petent form of the enzyme, changes have to occur: changes in oxidation state, the presence of external ions, an interaction with an electron donor or acceptor, and incubation with a substrate. Most of these processes will modify the metal coordination sphere and important conformational changes may occur to create an active (ready) state of the enzyme.

We have given examples that illustrate that control of the coordination sphere of the metal site is vital for catalytic activity. These examples also demonstrate the important dynamic aspects involved in the transformation of inactive into active species, and the importance of drastic rearrangements in order to build active sites that are ready for interactions with a substrate. The examples were divided into three main groups:

- Enzymes that are ready for action

- Enzymes in equilibrium between active/inactive states

- Enzymes isolated in unready states that require an activation step

A common team was followed, and we showed, with a number of examples, how ligands and electrons could control enzymatic activities in metalloenzymes. The first group illustrated cases that are ready for action and do not require activation. The two examples given were cytochrome $c$ nitrite reductase-ccNIR, which reduces nitrite to ammonia, and the copper nitrite reductase that reduces nitrite to NO. The other examples focused on metalloenzymes that are isolated in inactive states. The inactive enzyme has a full coordination site. The change in the coordination sphere following the removal of a crucial ligand generates a site that is ready to bind the substrate. In most cases, this activation also involves structural modifications and reductive steps are largely responsible for attaining active states of the enzymes. The examples chosen were: superoxide reductase, cytochrome $c$ peroxidase, cytochrome $c d_{1}$ nitrite reductase, hydrogenase and nitrous oxide reductase.

The same type of approach is clearly seen in other large enzyme groups, such as the mononuclear Mo- (and W-) containing enzymes. Mo and $\mathrm{W}$ are metals that can sustain higher coordination numbers, have a high affinity to $\mathrm{O}$ and $\mathrm{S}$, and stabilize different oxidation states at the metal site, usually with pterins. The unsatisfied coordination spheres of these metals introduce flexibility for substrate binding, and easy ways to insert and to abstract atoms, as seen in aldehyde oxidoreductase, xanthine oxidase, nitrate reductases, $\mathrm{CO}$ dehydrogenase and sulfite oxidase [72].

Acknowledgments Isabel Moura, Sofia R. Pauleta and José J. G. Moura would like to thank Fundação para a Ciência e Tecnologia (MCTES) for financial support (PTDC/QUI/64638/2006, POCI/QUI/ 57741/2004, POCI/QUI/57475/2004). 


\section{References}

1. Barton LL, Goulhen F, Bruschi M, Woodards NA, Plunkett RM, Rietmeijer FJ (2007) Biometals 20:291-302

2. Liu MC, Peck HD Jr (1981) J Biol Chem 256:13159-13164

3. Zumft WG (1997) Microbiol Mol Biol Rev 61:533-616

4. Kobayashi M, Matsuo Y, Takimoto A, Suzuki S, Maruo F, Shoun H (1996) J Biol Chem 271:16263-16267

5. Shoun H, Kim DH, Uchiyama H, Sugiyama J (1992) FEMS Microbiol Lett 73:277-281

6. Gonzalez PJ, Correia C, Moura I, Brondino CD, Moura JJ (2006) J Inorg Biochem 100:1015-1023

7. Zumft WG, Kroneck PM (2007) Adv Microb Physiol 52:107227

8. Brown K, Tegoni M, Prudencio M, Pereira AS, Besson S, Moura JJ, Moura I, Cambillau C (2000) Nat Struct Biol 7:191-195

9. Brown K, Djinovic-Carugo K, Haltia T, Cabrito I, Saraste M, Moura JJ, Moura I, Tegoni M, Cambillau C (2000) J Biol Chem 275:41133-41136

10. Einsle O, Messerschmidt A, Stach P, Bourenkov GP, Bartunik HD, Huber R, Kroneck PM (1999) Nature 400:476-480

11. Dodd FE, Van Beeumen J, Eady RR, Hasnain SS (1998) J Mol Biol 282:369-382

12. Williams PA, Fulop V, Garman EF, Saunders NF, Ferguson SJ, Hajdu J (1997) Nature 389:406-412

13. Cunha CA, Macieira S, Dias JM, Almeida G, Goncalves LL, Costa C, Lampreia J, Huber R, Moura JJ, Moura I, Romao MJ (2003) J Biol Chem 278:17455-17465

14. Jormakka M, Richardson D, Byrne B, Iwata S (2004) Structure 12:95-104

15. Bertero MG, Rothery RA, Palak M, Hou C, Lim D, Blasco F, Weiner JH, Strynadka NC (2003) Nat Struct Biol 10:681-687

16. Pettigrew GW, Echalier A, Pauleta SR (2006) J Inorg Biochem 100:551-567

17. Dias JM, Alves T, Bonifacio C, Pereira AS, Trincao J, Bourgeois D, Moura I, Romao MJ (2004) Structure 12:961-973

18. Echalier A, Goodhew CF, Pettigrew GW, Fulop V (2006) Structure 14:107-117

19. Echalier A, Brittain T, Wright J, Boycheva S, Mortuza GB, Fulop V, Watmough NJ (2008) Biochemistry 47:1947-1956

20. Pereira AS, Tavares P, Folgosa F, Almeida RM, Moura I, Moura JJ (2007) Eur J Inorg Chem 1:2569-2581

21. Santos-Silva T, Trincao J, Carvalho AL, Bonifacio C, Auchere F, Raleiras P, Moura I, Moura JJ, Romao MJ (2006) J Biol Inorg Chem 11:548-558

22. Adams MW, Jenney FE Jr, Clay MD, Johnson MK (2002) J Biol Inorg Chem 7:647-652

23. Fontecilla-Camps JC, Volbeda A, Cavazza C, Nicolet Y (2007) Chem Rev 107:4273-4303

24. De Lacey AL, Fernandez VM, Rousset M, Cammack R (2007) Chem Rev 107:4304-4330

25. Burlat B, Gwyer JD, Poock S, Clarke T, Cole JA, Hemmings AM, Cheesman MR, Butt JN, Richardson DJ (2005) Biochem Soc Trans 33:137-140

26. Kakutani T, Watanabe H, Arima K, Beppu T (1981) J Biochem 89:453-461

27. Murphy ME, Turley S, Adman ET (1997) J Biol Chem 272:28455-28460

28. Almeida MG, Macieira S, Goncalves LL, Huber R, Cunha CA, Romao MJ, Costa C, Lampreia J, Moura JJ, Moura I (2003) Eur J Biochem 270:3904-3915

29. Tocheva EI, Eltis LD, Murphy ME (2008) Biochemistry 47:4452-4460

30. Wijma HJ, Jeuken LJ, Verbeet MP, Armstrong FA, Canters GW (2007) J Am Chem Soc 129:8557-8565
31. Wijma HJ, Jeuken LJ, Verbeet MP, Armstrong FA, Canters GW (2006) J Biol Chem 281:16340-16346

32. MacPherson IS, Murphy ME (2007) Cell Mol Life Sci 64:28872899

33. Ascenso C, Rusnak F, Cabrito I, Lima MJ, Naylor S, Moura I, Moura JJ (2000) J Biol Inorg Chem 5:720-729

34. Jovanovic T, Ascenso C, Hazlett KR, Sikkink R, Krebs C, Litwiller R, Benson LM, Moura I, Moura JJ, Radolf JD, Huynh BH, Naylor S, Rusnak F (2000) J Biol Chem 275:28439-28448

35. Rusnak F, Ascenso C, Moura I, Moura JJ (2002) Methods Enzymol 349:243-258

36. Yeh AP, Hu Y, Jenney FE Jr, Adams MW, Rees DC (2000) Biochemistry 39:2499-2508

37. Adam V, Royant A, Niviere V, Molina-Heredia FP, Bourgeois D (2004) Structure 12:1729-1740

38. Lombard M, Houee-Levin C, Touati D, Fontecave M, Niviere V (2001) Biochemistry 40:5032-5040

39. Emerson JP, Coulter ED, Cabelli DE, Phillips RS, Kurtz DM Jr (2002) Biochemistry 41:4348-4357

40. Huang VW, Emerson JP, Kurtz DM Jr (2007) Biochemistry 46:11342-11351

41. Clay MD, Jenney FE Jr, Hagedoorn PL, George GN, Adams MW, Johnson MK (2002) J Am Chem Soc 124:788-805

42. Niviere V, Asso M, Weill CO, Lombard M, Guigliarelli B, Favaudon V, Houee-Levin C (2004) Biochemistry 43:808-818

43. Rodrigues JV, Victor BL, Huber H, Saraiva LM, Soares CM, Cabelli DE, Teixeira M (2008) J Biol Inorg Chem 13:219-228

44. Pauleta SR, Guerlesquin F, Goodhew CF, Devreese B, Van Beeumen J, Pereira AS, Moura I, Pettigrew GW (2004) Biochemistry $43: 11214-11225$

45. Gilmour R, Goodhew CF, Pettigrew GW, Prazeres S, Moura JJ, Moura I (1994) Biochem J 300(Pt 3):907-914

46. Alves T, Besson S, Duarte LC, Pettigrew GW, Girio FM, Devreese B, Vandenberghe I, Van Beeumen J, Fauque G, Moura I (1999) Biochim Biophys Acta 1434:248-259

47. De Smet L, Savvides SN, Van Horen E, Pettigrew G, Van Beeumen JJ (2006) J Biol Chem 281:4371-4379

48. Fulop V, Moir JW, Ferguson SJ, Hajdu J (1995) Cell 81:369-377

49. Lopes H, Besson S, Moura I, Moura JJ (2001) J Biol Inorg Chem 6:55-62

50. Farver O, Kroneck PM, Zumft WG, Pecht I (2003) Proc Natl Acad Sci USA 100:7622-7625

51. Vignais PM, Billoud B (2007) Chem Rev 107:4206-4272

52. Garcin E, Vernede X, Hatchikian EC, Volbeda A, Frey M, Fontecilla-Camps JC (1999) Structure 7:557-566

53. Volbeda A, Martin L, Cavazza C, Matho M, Faber BW, Roseboom W, Albracht SP, Garcin E, Rousset M, Fontecilla-Camps JC (2005) J Biol Inorg Chem 10:239-249

54. Albracht SP, Graf EG, Thauer RK (1982) FEBS Lett 140:311-313

55. Moura JJ, Moura I, Huynh BH, Kruger HJ, Teixeira M, DuVarney RC, DerVartanian DV, Xavier AV, Peck HD Jr, LeGall J (1982) Biochem Biophys Res Commun 108:1388-1393

56. Teixeira M, Moura I, Xavier AV, Huynh BH, DerVartanian DV, Peck HD Jr, LeGall J, Moura JJ (1985) J Biol Chem 260:89428950

57. Teixeira M, Moura I, Xavier AV, Moura JJ, LeGall J, DerVartanian DV, Peck HD Jr, Huynh BH (1989) J Biol Chem 264:16435-16450

58. Fernandez VM, Hatchikian EC, Camack R (1985) Biochim Biophys Acta 832:69-79

59. Fernandez VM, Hatchikian EC, Patil DS, Camack R (1986) Biochim Biophys Acta 883:145-154

60. Carepo M, Tierney DL, Brondino CD, Yang TC, Pamplona A, Telser J, Moura I, Moura JJ, Hoffman BM (2002) J Am Chem Soc 124:281-286 
61. Volbeda A, Charon MH, Piras C, Hatchikian EC, Frey M, Fontecilla-Camps JC (1995) Nature 373:580-587

62. Prudencio M, Pereira AS, Tavares P, Besson S, Cabrito I, Brown K, Samyn B, Devreese B, Van Beeumen J, Rusnak F, Fauque G, Moura JJ, Tegoni M, Cambillau C, Moura I (2000) Biochemistry 39:3899-3907

63. Haltia T, Brown K, Tegoni M, Cambillau C, Saraste M, Mattila K, Djinovic-Carugo K (2003) Biochem J 369:77-88

64. Ghosh S, Gorelsky SI, George SD, Chan JM, Cabrito I, Dooley DM, Moura JJ, Moura I, Solomon EI (2007) J Am Chem Soc 129:3955-3965

65. Ghosh S, Gorelsky SI, Chen P, Cabrito I, Moura JJ, Moura I, Solomon EI (2003) J Am Chem Soc 125:15708-15709

66. Chen P, Cabrito I, Moura JJ, Moura I, Solomon EI (2002) J Am Chem Soc 124:10497-10507
67. Chen P, DeBeer George S, Cabrito I, Antholine WE, Moura JJ, Moura I, Hedman B, Hodgson KO, Solomon EI (2002) J Am Chem Soc 124:744-745

68. Gorelsky SI, Xie X, Chen Y, Fee JA, Solomon EI (2006) J Am Chem Soc 128:16452-16453

69. Gorelsky SI, Ghosh S, Solomon EI (2006) J Am Chem Soc 128:278-290

70. Chen P, Gorelsky SI, Ghosh S, Solomon EI (2004) Angew Chem Int Ed Engl 43:4132-4140

71. Solomon EI, Sarangi R, Woertink JS, Augustine AJ, Yoon J, Ghosh S (2007) Acc Chem Res 40:581-591

72. Brondino CD, Romao MJ, Moura I, Moura JJ (2006) Curr Opin Chem Biol 10:109-114 